\title{
Dynamic and static tests of the safety foil for windows for composite glass interaction
}

\author{
Daniel Papán ${ }^{1, *}$, Zuzana Papánová ${ }^{1}$ and Lucia Figuli ${ }^{2}$ \\ ${ }^{1}$ University of Žilina, Faculty of Civil Engineering, Department of Structural Mechanics and Applied \\ Mathematics, Univerzitná 8215/1, 01026 Žilina, Slovak Repuplic \\ ${ }^{2}$ University of Žilina, Faculty of Security Engineering, Department of technical science and \\ informatics, Univerzitná 8215/1, 01026 Žilina, Slovak Repuplic
}

\begin{abstract}
The standard windows can be enhanced with safety foil. This types of foils are usually used for car windows. The paper shows how can the composite system created from glass plate and safety foil improve the mechanical resistance. The main task is to determinate affecting parameters for the impact or dynamic resistance. The various methods are showed in the paper. All results are based on the experimental investigation and load tests.
\end{abstract}

\section{Introduction}

Protection of people and environmental safety is currently an important task. There are lot of types of materials used in civil engineering. Their use is absolutely ordinary and makes life easier for us. These materials also include glass. Glass is often used in structures in combination with other materials. Common people encounter it in the form of windows, various glass panels or glazing. It has many advantages, but using it can be dangerous. Broken fragments are potential threat to human health. Therefore, it is necessary to avoid dropping these fragments after destruction [1].

\section{Safety film glass}

There are more options for object protection. The protections methods can be divided into three classes:

$$
\begin{aligned}
& \text { - Safety fittings } \\
& \text { - Safety glass } \\
& \text { - Safety foil glass }
\end{aligned}
$$

The best form of glass protection is a safety film to protect the glass against breakage. It is important to know the type of glass and the potential threats to damage it. The foil prevents the glass against separation, when the glass is broken. It is controlling the post-break behaviour of the broken fragments. The pieces are together attached to the film. This greatly

\footnotetext{
*Corresponding author: papan@uniza.sk
} 
enhances the safety of building occupants and protection of furnishings from damage caused by broken and flying glass pieces (Fig. 1).
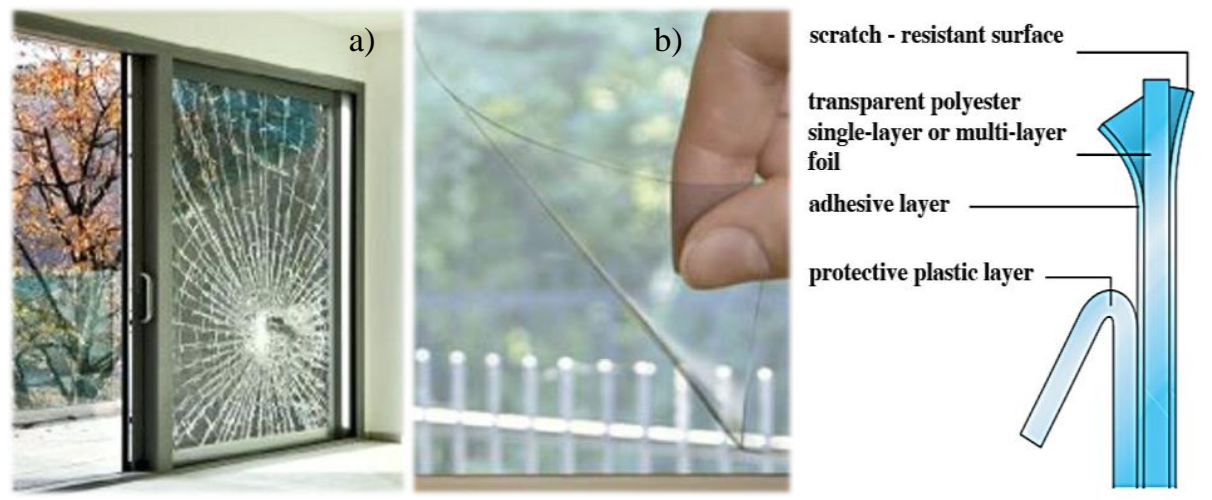

c)

Fig. 1. Safety foil examples: a) broken window with safety foil, b) safety window detail,

c) composition of the foil.

\subsection{Technical parameters of safety foil for window}

These foils consist of a thin, single-layer or multi-layer polyester construction. They are transparent (transmitting 80-90\% of daylight), thin and extra strong. They act as a shield on glass windows and doors. This protects the structures from burglary, vandalism or explosion. The attested foils are glued to the glass panel from the inside to the edge of the window frame. The glass must have a maximum thickness of $4 \mathrm{~mm}$.

Their mechanical, optical and solar parameters are different for a variety of foils types. An overview of technical parameters of some types is shown in Table 1.

Table 1. Mechanical, optical and solar parameters.

\begin{tabular}{|c|c|c|c|c|}
\hline $\begin{array}{c}\text { Mechanical } \\
\text { parameters }\end{array}$ & composition & strength on impact & $\begin{array}{c}\text { extension } \\
\text { after impact }\end{array}$ & $\begin{array}{c}\text { strength of the } \\
\text { adhesive layer }\end{array}$ \\
\hline $\begin{array}{c}\text { Range of the } \\
\text { parameters }\end{array}$ & $100-300[\mu \mathrm{m}]$ & $9,38-29,61\left[\mathrm{~kg} / \mathrm{cm}^{2}\right]$ & $125 \%$ & $0,19\left[\mathrm{~kg} / \mathrm{cm}^{2}\right]$ \\
\hline $\begin{array}{c}\text { Optical and } \\
\text { solar parameters }\end{array}$ & $\begin{array}{c}\text { reflected solar } \\
\text { energy }\end{array}$ & $\begin{array}{c}\text { transmitted solar } \\
\text { energy }\end{array}$ & $\begin{array}{c}\text { absorbed } \\
\text { solar energy }\end{array}$ & $\begin{array}{c}\text { ultra violet } \\
\text { block }\end{array}$ \\
\hline $\begin{array}{c}\text { Range of the } \\
\text { parameters }\end{array}$ & $10-65 \%$ & $12-81 \%$ & $9-56 \%$ & $94-99 \%$ \\
\hline
\end{tabular}

\section{Dynamic diagnostic of safety foils modulus of elasticity}

Another mechanical parameter of the foils is the modulus of elasticity. Its value can be determined by a simple dynamic test. This test is performed on a foil specimen. Its dimensions are determined taking into account the possibilities of the loading device.

\subsection{Theoretical approach}

The foil specimen is considered as one-dimensional element that can propagate waves. The propagating waves are expressed using a one-dimensional differential equation (1)

$$
\frac{\partial^{2} u}{\partial t^{2}}=v^{2} \frac{\partial^{2} u}{\partial x^{2}}
$$


The function $u(x, t)$ is the instantaneous deflection, that depends on the position $x$ and from time $t$. The parameter $v$ is the waves propagate speed along the foil and it depends on the thickness of the foil. When we generate a harmonic (sinusoidal) propagation across a foil, the function $u_{1}(x, t)$ can be expressed by the equation (2)

$$
u_{1}(x, t)=A_{1} \sin \left[\omega_{1}\left(t-\frac{x}{v}\right)\right]=A_{1} \sin \left[2 \pi f_{1}\left(t-\frac{x}{v}\right)\right]
$$

The sine argument has a positive sign, which takes into account the opposite direction of the wave along the $x$ axis [2]. The incident a reflected waves have the same frequency. By reflection the deflection changes to negative sign. The opposite waves with the same frequencies propagate through the safety foil. Final deflection includes the sum of the deflections of individual waves (Fig. 2).

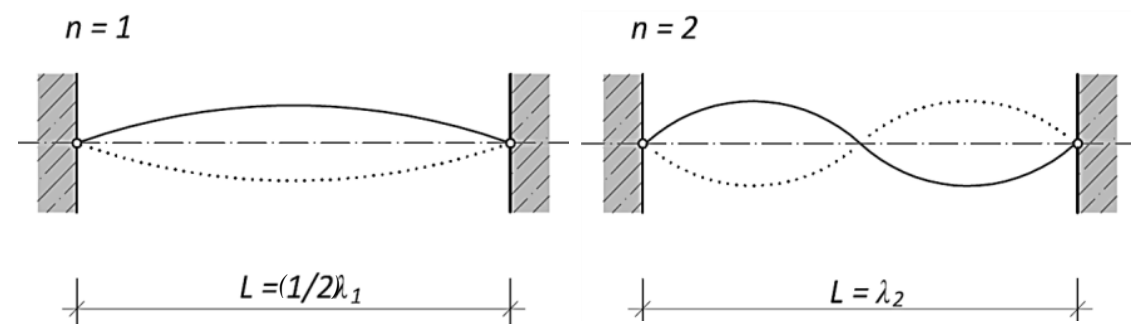

Fig. 2. Theoretical basic modes of the foil - first and second.

The foil support point $(x=0)$ cannot vibrate, it has zero deflection. The situation is different if the other support of the foil (it is fixed). Then only the waves of certain frequencies can propagate. The relationship between the frequency $f$, the wavelength $\lambda$ and the velocity $v$ of the harmonic wave can be expressed by the equation (3). This velocity $(v)$ depends on the unit mass per length of the foil specimen $(s)$ and the tension force $(F)$. Another possibility to express velocity is by modulus of elasticity $E$ and density $\rho$ (3)

$$
v=f \cdot \lambda=\sqrt{\frac{F}{S}}=\sqrt{\frac{E}{\rho}}
$$

The basic frequency of the foil vibration is called $f_{1}$. The foil frequencies fixed at both ends may be only multiples of the base frequency [4]. The basic wavelength $\lambda_{1}$ of the harmonic waves is equal to twice the length $L$ of the foil and all other wavelengths are fractions thereof (4)

$$
f_{1}=\frac{v}{2 L}=\frac{1}{2 L} \sqrt{\frac{F}{S}}=\frac{1}{2 L} \sqrt{\frac{E}{\rho}} ; \quad f_{n}=n \cdot f_{1} \quad \Rightarrow \quad \lambda_{n}=\frac{2 L}{n}=\frac{\lambda_{1}}{n}
$$

\subsection{Experimental investigation - dynamic test}

\subsubsection{Measurement progress}

Foil specimen is made of polyethylene terephthalate (PET) and it has dimensions of $300 \mathrm{~mm}$ x $10 \mathrm{~mm}$. Thickness of foil was $300 \mu \mathrm{m}$ and its unit mass per length is $45 \mathrm{~g} / \mathrm{m}$. The specimen was mechanically fixed between two steel plates. Then it was loaded with steel weights. The accelerometer was fixed on the foil. It was used original designed line by Brüel \& Kjær (BK) with system PULSE. This line consists of accelerometer (type BK 4508), coaxial cable, module and PC. Induced tension was simple tensile stress. Range of the forces was from 0.88 
$\mathrm{N}$ to $50.01 \mathrm{~N}$. Experiment is schematically shown in Fig. 3. Near fixing steel plate was applied the excitation by slide fingers typing.

a)

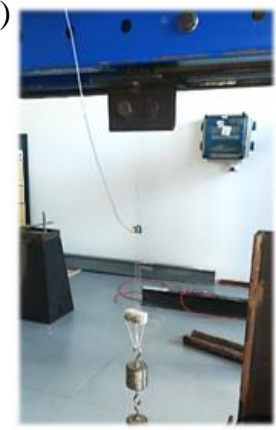

b)

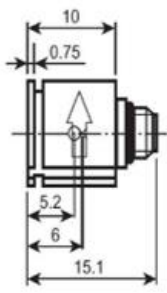

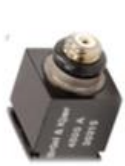

c)

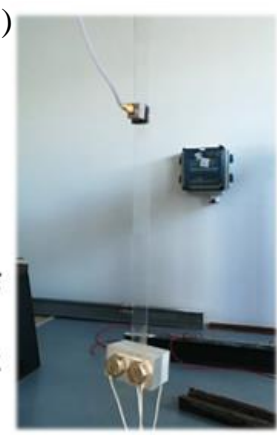

Fig. 3. Dynamic test of safety foil: a) the foil specimen load, b) the used accelerometer type, c) the accelerometer and the specimen fixing.

\subsubsection{Measurement results}

During the measurement the acceleration time histories were recorded from accelerometer situated in the middle of the foil specimen. The accelerometer was oriented horizontally to measure transversal wave propagation [3].
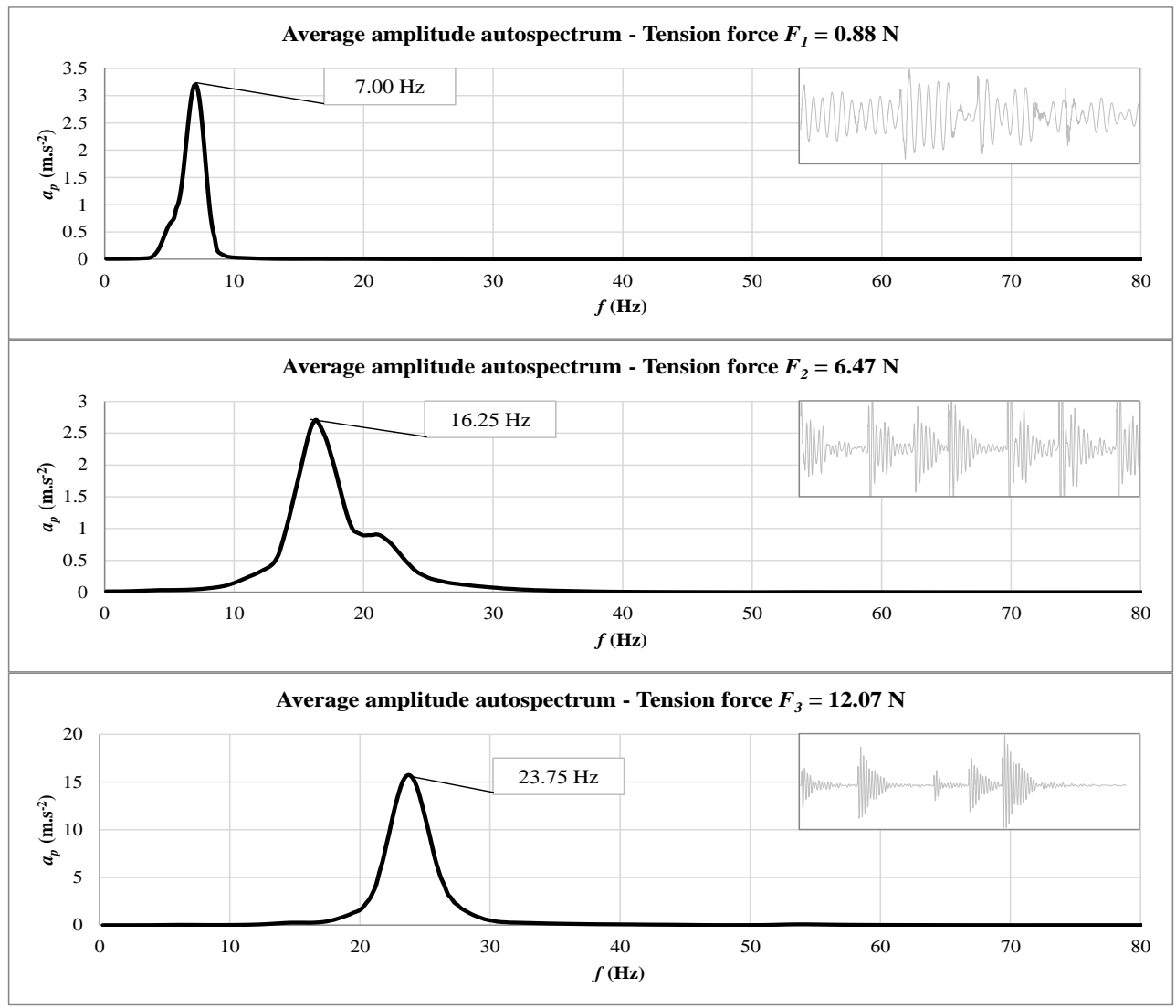

Fig. 4. Spectral analysis of the foil specimen vibration loaded by tensile forces $F_{1}, F_{2}$ and $F_{3}$. 
Tensile force was divided to seven steps depending on the range of the forces. Its values (depending on increasing weights) are in the second column of the Table 2. The measured records were processed in the BK PULSE system using spectral analysis module. The results of this spectral analysis were average amplitude transversal accelerations spectra. For each evaluated record by spectral analysis the significant dominant frequency were obtained. The further investigated parameters based on measured frequency and tensile force are summarized in Table 2. These parameters were calculated using theoretical approach described in chapter 3.1 .

On the Fig. 4. and 5. the average amplitude auto-spectra are shown. Auto-spectra for tension forces from $0.88 \mathrm{~N}-12.07 \mathrm{~N}$ used in experiment are shown on Fig. 4. Auto-spectra for tension forces from 17.66 $\mathrm{N}-50.01 \mathrm{~N}$ are shown on Fig. 5.
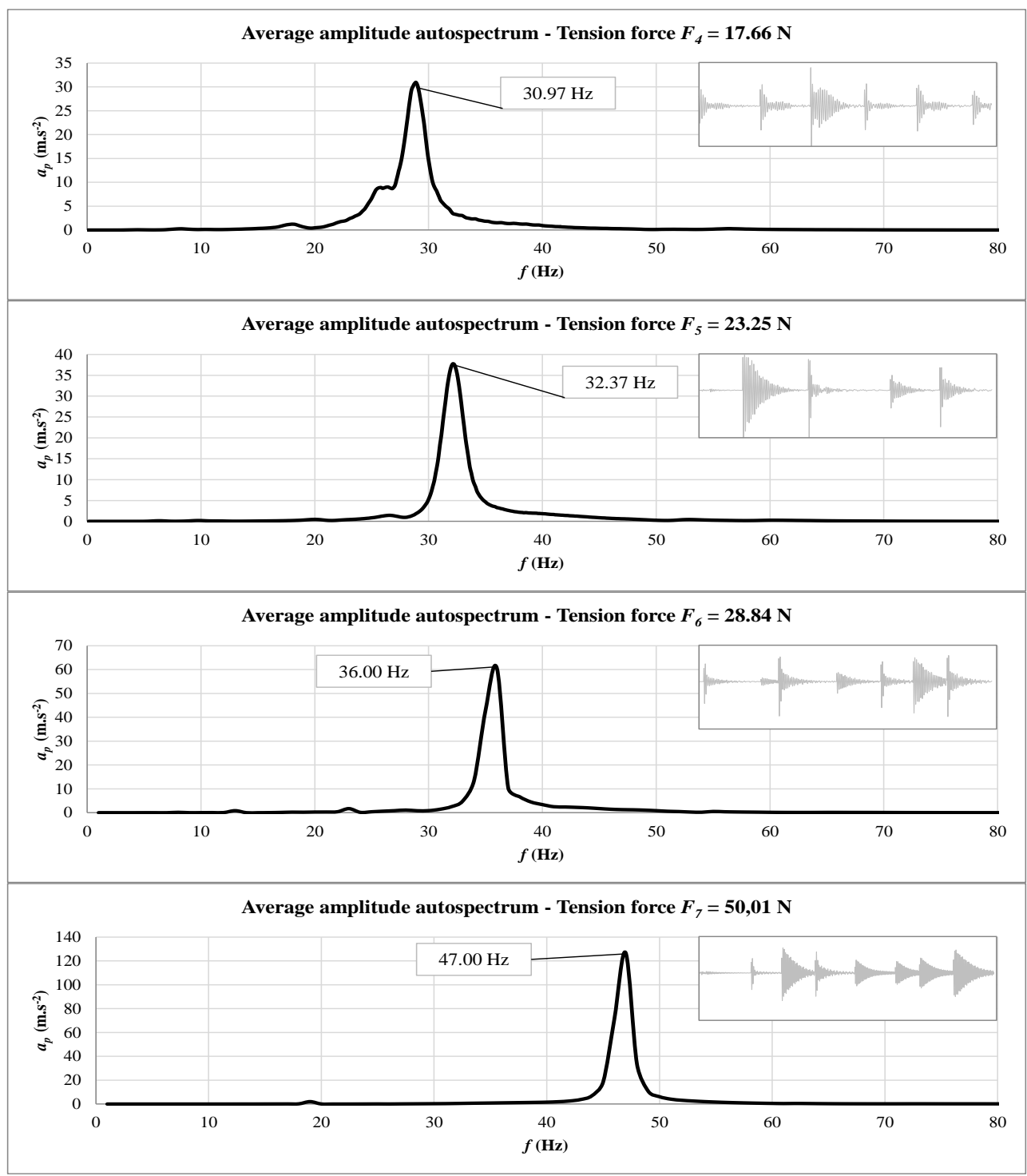

Fig. 5. Spectral analysis of the foil specimen vibration loaded by tensile forces $F_{4}, F_{5}, F_{6}$ and $F_{7}$. 
Table 2. Input and investigated parameters of the foil specimen.

\begin{tabular}{|c|c|c|c|c|c|c|c|c|}
\hline $\begin{array}{c}\text { Load } \\
\text { Cycle }\end{array}$ & $\begin{array}{c}\text { load mass } \\
m[\mathrm{~kg}]\end{array}$ & $\begin{array}{c}\text { tension } \\
\text { force } \\
F[\mathrm{~N}]\end{array}$ & $\begin{array}{c}\text { measured } \\
\text { frequency } \\
f_{(1)}[\mathrm{Hz}]\end{array}$ & $\begin{array}{c}\text { wave } \\
\text { velocity } \\
v^{(F)}\left[\mathrm{m} / \mathrm{s}^{-1}\right]\end{array}$ & $\begin{array}{c}\text { wave } \\
\text { velocity } \\
v^{(f 1)}\left[\mathrm{m} / \mathrm{s}^{-1}\right]\end{array}$ & $\begin{array}{c}\text { static } \\
\text { stress } \\
\sigma_{x}[\mathrm{MPa}]\end{array}$ & $\begin{array}{c}\text { static } \\
\text { strain } \\
\varepsilon_{x}\left[\mathrm{x} .10^{3}\right]\end{array}$ & $\begin{array}{c}\text { dynamic } \\
\text { elasticity } \\
\text { modulus } \\
E[\mathrm{MPa}]\end{array}$ \\
\hline 1 & 0.09 & 0.88 & 7.00 & 4.43 & 4.67 & 0.29 & 0.10 & 2847.50 \\
\hline 2 & 0.66 & 6.47 & 16.25 & 11.99 & 10.83 & 2.16 & 0.72 & 2709.46 \\
\hline 3 & 1.23 & 12.07 & 23.75 & 16.37 & 15.83 & 4.02 & 1.34 & 2900.77 \\
\hline 4 & 1.80 & 17.66 & 30.97 & 19.81 & 20.65 & 5.89 & 1.96 & 3126.85 \\
\hline 5 & 2.37 & 23.25 & 32.37 & 22.73 & 21.58 & 7.75 & 2.58 & 2848.20 \\
\hline 6 & 2.94 & 28.84 & 36.00 & 25.32 & 24.00 & 9.61 & 3.20 & 2844.01 \\
\hline 7 & 5.11 & 50.01 & 47.00 & 33.34 & 31.33 & 16.67 & 5.56 & 2819.72 \\
\hline
\end{tabular}

\section{Conclusions}

The main aim of the paper was to present possibilities of the windows glass protection by special foils. For the research of the real behaviour of this protecting element it is necessary to know the basic mechanical parameters. The modulus of elasticity is one of the most important input for FEM (Finite Element Method) modelling of whole window system. On tuned FEM model it is possible to make dynamical simulations solving the impact resistance of the protected window structure [5]. This paper shows one simplified method of modulus elasticity identification by the test. It is based on the fusion of basic theory of spring vibration and transversal wave propagation characteristics. Dependence between increasing transversal wave propagation, first natural frequency, acceleration, tension force amplitudes and stress can help determinate modulus of elasticity value. The physical phenomena are clearly seen in Fig. 4, 5. The resulting values are summarised in the Table 2. It is possible to evaluate average modulus of elasticity of this testing method as $E_{d y n}=2870 \mathrm{MPa}$. If this value is compared with standard stress-strain analysis $\left(E_{\text {stat }}=2750 \mathrm{MPa}\right)$ a small increase can be identified. It is caused by small stress of loading process (approximately $15 \%$ of yield strength). This type of analysis helps to model of composite glass-foil behaviour in special dynamic numerical simulations. The biggest advantage of this method is that no expensive testing equipment is required.

\section{References}

1. L. Benkovičová, Journ. My House, 9, 138-141 (BA, 2012)

2. T. C. A. Molteno, N. B. Tufillaro, Am. Journ. of phys. 72, 1157-1169, (2004).

3. Ch. Bedon, C. Amadio, Engin. Struc., 152, 320-334 (Elsev.,2017)

4. N. B. Tufillaro, Amer. Journ. of phys. 57 (1989).

5. Ch. Bedon, Ch. Louter, Comp. Struc., 167, 238-250 (2017) 